\title{
¿CRISIS DEL ESTADO O DESTRUCCIÓN DE LO PÚBLICO? CONSIDERACIONES EN TORNO A UNA TESIS DE MARIO GÓNGORA
}

\author{
Marcos García de la Huerta \\ Universidad de Chile \\ marcosgh@adsl.tie.cl
}

\begin{abstract}
Resumen / Abstract
La crisis del Estado en Chile en el siglo XX es un problema crucial para una nación que, según la tesis de Mario Góngora, fue "creada por el Estado". Este artículo analiza dos temas centrales de esta interpretación: 1) el significado de esa primacía estatal -si es, efectivamente, una propuesta descriptiva, sustentada en el uso empírico de la razón, o posee el mismo carácter de ficción constituyente de su inversa (la nación crea el Estado)-; y 2) la crítica de las "planificaciones globales", especialmente aquella iniciada con la reforma neoliberal del Estado (1973). Esta postura constituye una crítica historicista, conservadora, del neoconservadurismo, argumenta el autor. Esa primacía del Estado implica, por otra parte, una concepción de la política que la identifica con la acción de gobierno y asimila el poder con la dominación. Lo que está en juego, entonces, con la crisis del Estado sería la destrucción de la esfera pública, la privatización de la política.
\end{abstract}

PALABRAS ClaVE: Estado, nación, crisis, planificación global, historicismo.

\section{CRISIS OF THE STATE OR DESTRUCTION OF THE PUBLIC SPHERE? (ON A THESIS OF MARIO GÓNGORA)}

The crisis of the State in Chile during the XX century is a crucial question for a nation which was "created by the State", according to a thesis of Mario Góngora. This article analyses two main subjects of this interpretation: 1) the meaning of that primacy of the State over the nation -is it actually merely a descriptive proposition sustained in the empirical use of reason, or has the same fictional and constituent character of its reversal (the nation creates the State)-; and 2) the critic of the "global planning", particularly the neoliberal reform of the State during the military regime. This stance represents a kind of historicist, conservative, critic of neo-conservatism, argues the author. Otherwise, that primacy of the State would involve a conception of politics which identifies it with the governmental action and assimilate power with domination. What is at stake, then, with the crisis of the State would be the destruction of the public sphere, the privatization of politics.

KEY WORDS: State, nation, crisis, global planning, historicism, politics. 
R⿴囗十 Mi interés inicial en el Ensayo histórico sobre la noción de Estado en Chile de Mario Góngora y La fronda aristocrática de Alberto Edwards deriva del hecho de que nuestra autocomprensión ético-política-lo que se suele llamar identidad nacional-, se ha plasmado en gran parte a través de los relatos de nación, los que, a su vez, definen modos de escribir la historia. Ambos autores resaltan la idea del Estado fuerte y realizador como elemento fundamental en la consolidación del orden y estabilidad republicano. El tema central del Ensayo de Góngora es la crisis o "decaimiento" del Estado en el siglo XX, asunto que el autor aborda desde una perspectiva integradora, transversal: "estos ensayos, afirma, no se pueden adscribir a la historia política, social, económica o cultural; son historia de una noción, sin perjuicio de tocar aquellas materias en cuanto hagan comprensible esa noción; de otra manera, ésta sería una mera abstracción" ${ }^{1}$. El autor agrega una segunda aclaración: "se trata aquí esta historia en forma de ensayos, esto es, en una forma libre y abierta, sin ninguna pretensión de sistema, ni con las exigencias rígidas de una monografía [...] su objetivo es hacer considerar o mirar, sin tratar de demostrarlo, paso a paso"2.

Con estas dos indicaciones, Góngora quiere desmarcarse de las historias particulares - políticas, sociales, económicas-y alcanzar una visión sinóptica, "esencial" que, sin omitir esos asuntos parcelarios, no quede sujeta a exigencias sistémicas, y su capacidad reveladora surja del relato mismo. Góngora caracteriza el Estado, algo enigmáticamente, como un "organismo viviente"; más que su función económica, le interesa su papel forjador de la nacionalidad y del llamado ethos cultural; se resiste a verlo como una empresa de promoción de la riqueza o una "abstracta entidad fiscal"3. Advirtió tempranamente el peligro que representa la neutralización y repliegue del Estado en una "nación creada por el Estado", quiso evitarlo y al cabo lo profetizó. En este aspecto, su libro es la crónica de una derrota anunciada, pero la obra trasunta bajo el espesor de su información documental, una visión de conjunto de la historia de Chile, una de esas "grandes síntesis" que echaba de menos Guillermo Feliú Cruz como antídotos de los excesos de erudición. Esas visiones integradoras suponen mayor compromiso del autor; son el decantado de su reflexión y en ellas no habla solo el historiador con la autoridad del especialista sino el intelectual que "hace uso público de la razón" (Kant); entra en el debate como ciudadano, en términos igualitarios, sin eludir las cuestiones sustantivas de interés común. Permite así un diálogo y confrontación libre de las restricciones que impone la disciplina.

Góngora enmienda la interpretación de Alberto Edwards, quien atribuía un carácter "abstracto" o impersonal al Estado creado por Portales; en cambio, él afirma que se trata de un Estado aristocrático, no propiamente de señores feudales sino de terratenientes “sujetos al gobierno por su propio interés en el bien público. Lo 'impersonal' es propio Universitaria, Santiago, 2003 (Octava Edición), p. 60.

Ibíd.

Op. cit., p. 252. 
de una burguesía o de un proletariado industrial, nunca de una aristocracia"4. Pero ambos autores consideran ese Estado como el referente mayor de la historia de Chile. "La idea de un Estado configurado desde entonces (1830), gracias al pensamiento de Portales, es a mi juicio, afirma Góngora, la mayor y la mejor interpretación de la historia del siglo pasado: la génesis, el auge y la caída de la concepción portaliana estructuran, en la intuición de Edwards, al acontecer nacional desde 1830 hasta [por lo menos] 1891". Llama la atención que Edwards conciba el Estado portaliano en el momento de su ocaso, en los años veinte. La idea nace, pues, bajo el signo de la nostalgia, como reparo simbólico, diríamos -a riesgo de hacer algo de sicoanálisis-, de un sentimiento de pérdida: el "Estado en forma", como él lo llama, ya no existe, pero hay que canonizarlo porque merece vida sempiterna.

La crisis del Estado -el tema de Góngora- se puede entender también como una crisis de lo público, asociada con la mercantilización y la degradación de la política. Internamente, este fenómeno se manifestaría en la burocratización del Estado y en el creciente predominio de la "cuestión social"; en las relaciones exteriores, se traduce en la mengua del patriotismo y la preponderancia que adquieren las ideologías pacifistas: "Otro rasgo capital que pone de manifiesto la diferencia profunda con el Chile del siglo XIX: mientras éste acepta la guerra y anhela la expansión y glorificación de Chile por sobre todo, la generación del año 20 es pacifista hasta el escándalo [...] Es que, para ellos lo social como un ideal, sobrepasa 'lo nacional' [...empiezan a primar] los factores que llamaríamos económico-sociales" "6 . El influjo de la guerra en la formación de la nacionalidad merece atención especial y hemos de volver sobre ello.

La tesis según la cual “en Chile el Estado creó la nación” es provocativa, porque invierte el papel que suele atribuirse a la nación en la génesis del Estado. Góngora sostiene la paradoja de una nación criatura del Estado, es decir, atribuye un carácter constituyente al "Estado orgánico", lo que haría la gran diferencia con el Estado del siglo XX, que se torna reactivo y de gestión. El mismo hecho de llamar "ensayo" a la obra y hablar de "noción" en lugar de "concepto" de Estado, apunta en esa dirección: la noción no pretende el rigor del concepto, no quiere ser teoría. Sin embargo, queda abierta la pregunta acerca del estatuto de esta fórmula, por demás problemática, porque altera el carácter constituyente que el derecho y la teoría política le reconocen a la nación respecto del Estado en la república moderna. La tesis pretende un carácter empírico, al afirmar que "en Chile el Estado creó la nación" y que en el siglo XX ese rasgo activo y creador se desvirtúa, etc. Sin embargo, no se ve cómo el poner al revés una proposición jurídico-política podría transformarla al punto de adquirir un carácter distinto al del original. Góngora no es ajeno a esta dificultad, pues en la línea final

4 Op. cit., p. 79-80. Alberto Edwards, La fronda aristocrática, Universitaria, Santiago 1992.

Op. cit., p. 74.

Op. cit., p. 159. 
del Ensayo, modifica esa formulación: "es el Estado el que ha dado forma a nuestra nacionalidad"7.

"Portaliano", por otra parte, es el Estado que no se aparta de la búsqueda y realización del bien común, y cuya autoridad no se somete a los partidos ni a los intereses particulares. Su "desvanecimiento" se puede entender, entonces, como degradación de la política. Es eso lo que Góngora advierte que se produce en la segunda mitad del siglo, culmina en 1891 y llega a término en los años veinte con el predominio de la "democracia de masas”. Es ilustrativa al respecto su respuesta a la pregunta: “QQué está pasando en Chile, profesor, que esas son las principales noticias de los diarios?”. Uno de ellos decía: 'asesino sádico anda suelto'; otro: 'horroroso crimen de descuartizada', Góngora responde: "Lo novedoso es que todos los titulares son policiales; se debe a que no hay política" 8 . Quiere decir que no se hace política: el Estado se ha vuelto reactivo, escenario de pugnas de poder e instrumento de realización de agendas personales.

Pero el debilitamiento del Estado no es un fenómeno solo local: “también se da en multitud de casos, señala el autor, salvo en las superpotencias" ". Él asocia la crisis del Estado con la globalización política: "esta mundialización de la política, escribe, es mirada por algunos pensadores -Toynbee, por ejemplo- como un decisivo progreso". En cambio, él la considera una amenaza: "Un Estado mundial puede significar [...] la más terrible tiranía, de la cual ya nadie podrá escapar en parte alguna" ${ }^{10}$. Góngora no está solo en este rechazo de un Estado global: Kant sostenía que un Leviatán mundial impondría un "despotismo sin alma"; y tampoco podría cumplir una función pacificadora entre los Estados, análoga a la que Hobbes le asignaba al Leviatán en los conflictos entre individuos. "La anexión de todos por una potencia vencedora, que se convierte en monarquía universal", impondría un internacionalismo militar, un "despotismo sin alma" 11 . Ni la guerra misma es "tan incurablemente mala como la fosa de un Estado universal" 12 .

La globalización plantea, sin embargo, un problema adicional, y es que en el siglo XX ya no es posible ni verosímil un relato estrechamente nacional. La historia de Chile del siglo XIX era -o creía ser- "puertas adentro", por así decirlo: se podía contar como la historia de un cuerpo político cuyo desarrollo posee su propio logos y se estructura en torno a la transformación de una "aristocracia terrateniente" en "oligarquía plutocratizada"13. La globalización política altera esa situación y establece nuevas

Op. cit., p. 305 ( sin cursivas el original).

Entrevista de Raquel Correa en El Mercurio (9-12-1984) incluida en el Ensayo.., op. cit., p. 331. ¿"No hay política" o no hay democracia en 1984? En todo caso, en democracia se continuó con la misma Constitución de 1981 y con la misma estrategia económica. Treinta años después, no ha habido definiciones políticas de esa envergadura.

Op. cit., p. 272.

Ibíd.

Hacia la paz perpetua, trad. M. Cristina García, Buenos Aires: Ladosur, 2004, pp. 55-56. La religión dentro de los límites de la mera razón. Alianza, Madrid, 1986, p. 205n.

Ensayo...Op. cit., p. 265. 
coordenadas. La pregunta que surge, entonces, es hasta qué punto la crisis en cuestión es un fenómeno de la misma índole que la construcción del Estado. La misma idea de decaimiento pierde significado específico si toda la historia, de Portales en adelante, es un proceso de caída. El relato respectivo, ¿sigue siendo una 'historia de Chile', centrada en ese sujeto superlativo y con nombre propio -el Estado portaliano-, o ha comenzado una historia en Chile, descentrada, "sin sujeto" o relativamente anónima, que obedece a exigencias de una economía globalizada y de un Estado mundial en gestación? "Ya no hay política" quiere decir también: "ya no hay historia", hay una dificultad o incapacidad de hacer historia, y falta la figura del héroe civil del Estado omnipotente: falta un Teseo. Por otra parte, los conflictos bélicos cambiaron radicalmente de signo desde la Primera Guerra Mundial. La Guerra de Independencia fue forjadora de nacionalidad: creó un sentido de comunidad y autonomía; la Guerra del Pacífico fue una "guerra nacional", que reforzó el nacionalismo y la idea de territorialidad asociada al Estado. Pero, ¿se puede decir otro tanto de las guerras civiles o atribuir análogo significado a las guerras actuales y a las del siglo XX? ¿No se sustenta esa idea de la guerra, creadora de identidad, en los mismos conceptos decimonónicos de nación homogénea y de soberanía territorial, es decir, en una idea de soberanía asociada más al territorio y al patrimonio, a la patria y al patriotismo, que al demos y a la 'soberanía popular'? Si el Estado portaliano se debilita y decae junto con el surgimiento de la "cuestión social” y el auge del pacifismo, ¿no significa que su fortaleza requería de la guerra y se sustentaba en la coerción? ${ }^{14}$. Si es así, no había que esperar su decadencia para advertir su debilidad; su "decaimiento" sería una necesidad derivada de su propio carácter de mito fundador, autoafirmador, y de su anacronismo. Se requeriría, entonces, más que una "historia de la noción de Estado", una genealogía del Estado, que incluyera el origen, pero también la diferencia y distancia con él, que renunciara a la magnificación del comienzo y a la pretensión de hacer valer el Estado portaliano como clave de la historia ${ }^{15}$. La historia escrita en clave portaliana realza la función constituyente, "orgánica", del Estado, pero hace como si el resto del mundo no existiera. ¿Qué es lo que entra en crisis, entonces, con la mundialización: el mito fundacional del Estado o esa ficción insostenible? Un Portales integrado a la ideología del Estado y canonizado como su héroe civil, ¿no entra en esas formas infecundas de la historia a las que Nietzsche llamó “anticuaria” y "monumentaria”, y que Góngora, ciertamente, rechazaría? Lo que entra en crisis, junto con el Estado, es sobre todo la política: la dimensión pública de la existencia: la globalización significa que la política es permeada por los intereses y redefinida como "emprendimiento".

14 "No hay nada más terrible que un estamento bárbaro de esclavos que haya aprendido a considerar su existencia como una injusticia", Nietzsche, "Die Geburt der Tragödie", Werke in drei Bänden, Karl Hanser Verlag, München I, 18, p. 100 (El nacimiento de la tragedia. Madrid: Aguilar, 1932).

15 Sobre genealogía: Gilles Deleuze, Nietzsche y la filosofia, Anagrama, Barcelona, 1971; Michel Foucault, Nietzsche, la genealogía, la historia, Pre-Textos, Valencia, 2000; Nietzsche, "Von Nutzen und Nachteil der Historie für das Leben", Werke, I, pp. 209 ss. (Intempestivas, "De la utilidad y desventaja de los estudios históricos para la vida"). 
Aunque la globalización es un fenómeno político, como bien señala Góngora, se asocia y se sustenta en alguna medida en el poder de la técnica moderna, cuyo carácter incondicionado e irrestricto pone en entredicho el paradigma de la soberanía, y pone en jaque también aquello que ha constituido hasta ahora la forma histórica del habitar humano. Junto con multiplicar la productividad del trabajo, la técnica favorece la formación de superpotencias que amenazan la existencia misma de los Estados nacionales. Hasta no hace mucho, se pensaba que la tecnología, además de un instrumento de progreso, podía ser un arma de liberación. Pero hoy las naciones que no llegaron a ser potencias industriales parecen haberse rendido: aceptaron el papel de productores primarios que les asignaba la división internacional del trabajo y ya no fabrican ni un tornillo; es más: remacharon esa condición a la hora de defender su patrimonio genético agropecuario ${ }^{16}$.

La profusa publicidad sobre el desarrollo a la vuelta de la esquina oculta y hace olvidar la capitulación frente al desafío de la llamada sociedad del conocimiento. La estrategia de desregulación significó para Chile resignar la posibilidad de un desarrollo sustentable. Cuando se diseñó esa estrategia, se la justificaba prometiendo una "segunda fase" exportadora, en la que se acrecentaría la productividad y se agregaría más valor. Al cabo de veinte años, de esa "segunda fase" nunca más se habló: no se quiere ni siquiera haber hablado; y se importa desde alambre de cobre hasta vinos y frutas.

Propongo dos lecturas de este libro: desde luego, siguiendo la línea antes esbozada, se puede leer como una suerte de manifiesto o pronunciamiento ante la crisis de lo público. El propio autor, por lo demás, en la sección final, hace explícitas sus aprensiones sobre el presente. En un Anexo que bien podría ser el Prólogo, incluye el Balance patriótico de Vicente Huidobro. Allí se lee: "una nación no es una tienda, ni un presupuesto una Biblia [...] Socios no es lo mismo que ciudadanos". Góngora haría suyas, sin duda, estas palabras. El Ensayo mismo se deja leer como una suerte de balance patriótico: apareció en 1982, en plena dictadura militar tras casi una década de "liberalismo salvaje". El papel "subsidiario" que asume entonces el Estado significa que éste interviene para imponer el mercado. Junto con implantar la "soberanía del mercado", el principal agente modernizador y socializador, el Estado, se autoneutraliza y anula. ¿Podía ser sin consecuencias? Nuestra cultura, para bien o para mal, ha sido Estado-céntrica; sea que se trate de la educación, de la salud, del "combate a la pobreza", de una crisis económica o de cualquier otro asunto sustantivo, el referente obligado es el Estado. La desregulación de los mercados, junto con

16 La aspiración a convertirse en "potencia alimentaria", lo mismo que la canturreada "soberanía alimentaria", han derivado en retórica vacía: las leyes chilenas, en lugar de proteger las semillas nativas y las tradicionales aclimatadas utilizadas en la pequeña y mediana agricultura, han concedido garantías a las transnacionales, permitiéndoles patentar los vegetales producidos a partir de las semillas nativas. El Estado chileno no ha ratificado instrumentos internacionales de protección de la biodiversidad como el Protocolo de Cartagena sobre Bioseguridad ni el Protocolo de Nagoya (2010) sobre Acceso a los Recursos Genéticos. 
expandir la producción, agudizó un vacío estratégico que en parte llenaba el Estado. El mismo crecimiento agudizó algunos problemas más o menos endémicos, como la monoproducción exportadora, el escaso valor agregado, una matriz energética poco diversificada, la escasa o mínima transferencia tecnológica, y la casi nula inversión en investigación científica y en tecnologías adecuadas. El repliegue del Estado dejó un vacío que tuvo múltiples efectos; la privatización de los puertos, por ejemplo, dejó en manos de las empresas la responsabilidad de resolver los conflictos laborales. De acuerdo a la ley, el gobierno se declara neutral: es un conflicto entre privados, y las empresas -especialmente las exportadoras de bienes corruptibles-, quedan frente a la disyuntiva de tener que rendirse ante los reclamos de los trabajadores o pedir la intervención de la fuerza pública. Análoga figura se repite con la privatización de la energía: se dejó a la iniciativa privada la definición de nuevos proyectos, que la autoridad aprueba o rechaza, pero no define políticas generales. Los resultados han sido: escasa diversificación de la matriz energética, encarecimiento de la energía, pérdida de competitividad, incertidumbre en cuanto a suministros y precios a futuro, pérdida de mercados. Las propias empresas terminan exigiendo de la autoridad la definición de una política energética.

La privatización implica mercantilización, es decir, monetarización. En principio, es posible mercantilizarlo todo; no es que el dinero pueda comprarlo todo, pero es posible hacer como si pudiera, es decir, hacer transable lo que no se transaba y ponerle precio a todo lo que se creía no negociable. Ciertas actividades, sin embargo, no permiten que su monetarización se realice impunemente. La mercantilización no es gratuita: altera el carácter de lo transado y, al cabo, modifica la sociedad entera, porque la ganancia, que es el alma de los negocios, no puede constituirse en el alma del cuerpo político. La mercantilización perfeccionada desintegra el colectivo y constituye un límite de la estrategia privatizadora. La falta de políticas públicas en materia de educación, salud, inmigración, desarrollo de las zonas extremas son de sobra conocidas; en este último caso, ha alentado los afanes expansivos de los vecinos. La falta de política inmigratoria dejó a miles de exiliados librados a su propia suerte y ha dificultado el retorno de sus hijos, muchos de ellos graduados en universidades europeas y altamente calificados; en cambio, esa misma carencia de política inmigratoria ha facilitado el ingreso de narcotraficantes, lumpen y prostitutas baratas.

Cuando se publicó el Ensayo, estas cuestiones aún no alcanzaban la relevancia que adquirieron después. La protección del medioambiente, la seguridad ciudadana y los conflictos limítrofes, que son el pan nuestro de cada día, son asuntos que entran de lleno en la grilla conceptual de Góngora. El problema que él detectó -la crisis del Estado y la carencia de política-, no queda superado con la actual proliferación de movimientos ciudadanos y grupos de presión; y el rebrote de la política en las calles o su desplazamiento a tribunales confirman la justeza de su análisis. Inicialmente cautivado por los cantos de sirena portalianos de la dictadura, Góngora salió pronto del engaño, justamente a raíz de la reforma neoliberal del Estado. "La planificación ha partido de cero, escribe, contrariando o prescindiendo de toda tradición, lo que siempre trae consigo revanchas culturales. El neoliberalismo no es un fruto propio de nuestra 
sociedad, como en Inglaterra, Holanda o Estados Unidos, sino una 'revolución desde arriba', paradójicamente anti-estatal, en una nación formada por el Estado"17.

Góngora roza en este punto una cuestión que ha sido preocupación permanente en nuestra América, desde sus inicios: la asimilación indiscriminada, mimética, de formas culturales ajenas y heteróclitas. El Estado autárquico, supuestamente "creador", es refractario a las "doctrinas anti-estatales", que hacen caso omiso "de la idiosincrasia de los pueblos", pero cabe preguntar si no es enteramente funcional a las formas culturales importadas, y si "la idiosincrasia" es una instancia conceptual suficiente. La monarquía, sobre todo la del siglo XVI y XVII, es el emblema del Estado que prescinde de las tradiciones y arrasa las culturas vernáculas: es, por excelencia, el que construye, no solo "desde arriba" sino sobre la luna, por así decirlo. El "genio" de Portales consistiría en haber reproducido ese modelo jerárquico, coercitivo y virtualmente opresivo, procurándole apariencia republicana; un "genio", por tanto, que congeniaba bastante bien con lo que la mitología del romanticismo llamó el "genio del pueblo". Aunque sea entendible y, hasta cierto punto, justificable a comienzos del siglo XIX, el punto es si acaso ese Estado puede constituir un padrón o modelo todavía vigente.

Llama la atención, asimismo, que Góngora incluya la política neoliberal entre las "planificaciones globales", porque se suele entender la desregulación como contraria a los planes y sinónimo de liberalismo económico. Pero la desregulación responde, en efecto, a un plan o estrategia cuyo diseño constituye un verdadero golpe de mercado paralelo y complementario al golpe de Estado. Este tipo de ingeniería social: "quiere partir de cero, escribe Góngora, sin hacerse cargo de la idiosincrasia de los pueblos ni de sus tradiciones culturales" ${ }^{18}$. Se refiere a las ideologías globales en general, incluido el social cristianismo, el marxismo y el neoliberalismo. La Declaración de Principios (1974), el Acta fundacional del régimen militar, establece la "subsidiariedad" del Estado como uno de ellos; se ha convertido, señala nuestro autor, en "el principio casi único" y ha derivado en "una tendencia anti-estatal"

Góngora se opuso al neoliberalismo por razones "históricas"; anticipó los límites de la mercantilización sin abandonar su mirada de historiador, ajeno por completo al economicismo ortodoxo. ¿Habría, entonces, una argumentación historicista que debilita la tesis del Ensayo? ¿Es posible juzgar el papel del Estado -o el de la economía- sin alguna suerte de teoría y, sobre todo, omitiendo que el repliegue del Estado obedece a una lógica global, y que la liberalización de los mercados es una doctrina económica funcional a ella?

De estas preguntas surge una segunda lectura, crítica. El origen estatal de la nación reviste ciertas implicancias y dificultades relativas al concepto de Estado y a la idea de la política. Una nación nacida de su misma organización política es, como decíamos, algo paradójico, provocador y hasta contradictorio. Se entiende que es la 
nación la creadora del Estado y su razón de ser, que organizarse en un Estado responde a necesidades estratégicas y de supervivencia de la nación misma.

La fórmula "el Estado crea la nación" tiene cierto aire hegeliano, aunque Hegel no llega a separar completamente el Estado respecto de la "sociedad civil". En tanto expresión política y espiritual del pueblo, el Estado es su núcleo estructurador, su "voluntad racional" y no alcanza a ser productor o creador. El filósofo italiano Giovanni Gentile procura una fórmula más propiamente hegeliana a esa relación, al señalar: "si el Estado crea la nación, la nación crea el Estado", expresión que cierra el círculo, a pesar de que el Estado gentiliano-mussoliniano enfatiza el primer tramo de la frase. Octavio Paz, refiriéndose a México, escribe: "tuvimos un Estado y una Iglesia antes de ser una nación". Esto es algo distinto a la tesis analizada, porque la fórmula del mexicano es descriptiva: invoca solo una precedencia cronológica y, lejos de omitir al Estado colonial, se refiere sobre todo a él y a la Iglesia ${ }^{20}$. Ambos son anteriores a la nación mexicana, pero Paz no habla de creación y no se refiere en particular al México republicano. En cambio, si es el Estado republicano el creador, quiere decir que la nación comienza a existir gracias a una acción fundadora. Para ser comienzo, el Estado tiene que crear ex nihilo una nación "que no existiría sin él". "La nacionalidad chilena ha sido formada por un Estado que ha antecedido a ella, a semejanza, en esto, de la Argentina; y a diferencia de México y del Perú, donde grandes culturas autóctonas prefiguraron los Virreinatos y las Repúblicas" 21 . Lo que habría antes de la formación del Estado sería un sentimiento de "patria" o el amor al terruño. Fueron entonces las sucesivas guerras, desde la de la Independencia hasta la Guerra del Pacífico, "las que han ido constituyendo un sentimiento y una conciencia propiamente "nacionales", la "chilenidad". Y concluye: "Son las guerras defensivas u ofensivas las que a mi juicio han constituido el motor principal"22.

Las naciones sin Estado viven constantemente amenazadas, precisamente, por los Estados-nacionales. La constitución como Estado es un seguro de vida para la nación misma y, a la inversa, los Estados necesitan crear lealtades nacionales a su medida para subsistir. Entre ambos existe cierta sinergia, una relación simbiótica: la nación encuentra en el Estado su garantía de permanencia y el Estado, a su vez, para ser eficaz, crea y desarrolla alguna modalidad de nacionalismo, de imaginario nacional. La forma de representar esta relación no es neutra o indiferente, porque a través de la primacía del Estado o de la nación se expresan distintas maneras de concebir la política. El "Estado creador de la nación", traduce una vieja concepción de la política que la identifica con el gobierno del Estado y, a su vez, asimila el poder con la dominación. La verdadera historia será la crónica del Estado y sus agentes, la historia "gloriosa", del "Estado en forma" o "Estado orgánico", la que magnifica a los protagonistas del relato y deja en

20 Octavio Paz, Tiempo nublado, Seix Barral, Barcelona, 1983, p. 151.

21 Góngora, op. cit., p. 71.

22 Op. cit., p. 73. 
penumbra, invisible, a la nación anónima. El "Estado matriz" de la nación da la espalda al demos y reproduce el carácter autocrático del Estado colonial.

El reparo, en síntesis, es el siguiente: la idea del "Estado matriz de la nación"23 deja intacto el problema de la fundación y crea una serie de dificultades y equívocos asociados a una concepción Estado-céntrica del poder y la política. Para ser creador de nación, el Estado ha de ser un órgano separado del cuerpo civil, autogenerado y fundado en sí mismo: eso supone, desde luego, un Estado autárquico. Pero, sobre todo, supone una idea de nación válida solo a partir del siglo XIX, cuando se la concibe asociada al Estado y se la identifica con él, bajo la forma del Estado-nación. Esta asimilación es válida para la nación política, que en la América hispánica, efectivamente, no existía antes de la Independencia, pero omite el demos, la "nación" protopolítica, que preexistió a la nación de la soberanía. La república no es el comienzo absoluto del Estado y éste no es el único agente creador o "civilizador". La Iglesia, sin ir más lejos, cumplió un papel decisivo en la formación de los "reinos". Con la idea de un Estado autogenerado, que "crea nación", se da por resuelta la cuestión, absolutamente crucial, de la legitimación del poder. Desde el punto de vista jurídico, es la nación la que legitima el Estado; si se invierte la fórmula, necesariamente se deslegitima la república. ¿Es casual que Góngora prefiera calificar el Estado de acuerdo al siglo y no por su carácter, e incluso en el título omita el adjetivo "republicano"?

"Nación" durante el siglo XVIII y gran parte del siglo XIX, era simplemente "la colección de habitantes de alguna provincia, país o reino" 24 . La idea de una "nación" construida desde arriba por el Estado y, al cabo, por el sujeto que lo conduce, es muy moderna, sin duda, pero no surge de una constatación empírica, corresponde más bien a la episteme, al modelo técnico-fabril del invento o del "gran hombre mecánico": el otro nombre del Leviatan. Al situar la política exclusivamente en el Estado, se reproduce la lógica del poder gubernamental en el discurso y, sobre todo, se impone un modo de pensar la política que la concibe exclusivamente como acción de Estado, y al poder, centralizado en él. Los partidos, la Iglesia o cualquier agente distinto del ejecutivo quedan minimizados, incluso el ejército, por más que se afirme la guerra como formadora de nacionalidad.

Los comienzos consisten, precisamente, en que el pueblo -el otro nombre de la "nación"-, actúa al margen del ordenamiento político-institucional; sin esa precedencia no se entienden las proclamaciones y actas de independencia o de autonomía o autodeterminación. ¿"Auto" de quién, si no hay un sujeto que pueda darse una constitución y un orden político? A ese sujeto previo, anónimo y en cierto modo imaginario, le llamamos nación. Es una ficción, claro está, pero una ficción constituyente. El Estado-

23 Op. cit., p. 59. "El Estado es la matriz de la nacionalidad: la nación no existiría sin el Estado, que la ha configurado a lo largo de los siglos XIX y XX".

24 En Diccionario de la Real Academia Española hasta las ediciones de 1884; con posterioridad, define nación como "un cuerpo político que reconoce un centro común supremo de gobierno" (Eric Hobsbawm, Naciones y nacionalismo desde 1780. Crítica, Barcelona 2004, p. 23). 
nación así constituido es Estado ficción; pero, si no se admite este carácter ficcional del Estado nacional, no hay modo de salir de la contradicción del "Estado creador", de la nación creada ex nihilo y de la República como comienzo absoluto; vale decir, de "una nación que no existe sin Estado" y de un cuerpo político que, a su vez, existe sin partidos, sin organizaciones intermedias, en suma, sin ciudadanía. En otras palabras, tiene que haber en el comienzo un "nosotros el pueblo" o un "nosotros la nación", que proclame, en nombre de "la voluntad popular" o del "interés general", una "verdad" hasta entonces no reconocida. Quienes se atribuyen esa representación del pueblo, de su voluntad o de sus intereses, pueden invocar que dicha verdad es, por sí misma evidente o pretender que ella responde a designios divinos o a leyes de la naturaleza, pero en rigor se trata de legitimar un acto constituyente. Y la verdad en cuestión es esa misma capacidad del "pueblo" - de los vecinos notables reunidos en asamblea-, de proclamarse "independientes", de darse ellos mismos un gobierno o eventualmente constituirse como Estado. Esta serie de actos, reuniones, deliberaciones, resoluciones y proclamas, se sintetiza en la fórmula "la nación crea un Estado", pero esta verdad es un axioma de la razón política, un postulado de la razón práctica, diría un kantiano. No hay forma de darle carácter empírico a esta "verdad", tampoco a su inversa: no por dar vuelta una ficción constituyente, se convierte en "realidad empírica" o en "verdad de hecho".

El enunciado final de la tesis de Góngora mitiga considerablemente las formulaciones iniciales. Así, "el Estado matriz de la nacionalidad” y "la nación (que) no existiría sin el Estado" se convierten en: "es el Estado el que ha dado forma a nuestra nacionalidad". Pero "dar forma" es algo muy distinto a "crear", y no constituye un rasgo específico: lo mismo podría afirmarse del Estado uruguayo, del argentino o incluso del peruano o mexicano, y aun del alemán o del italiano.

Surge, entonces la pregunta sobre si el desarrollo de la crisis del Estado no conduce a la revisión de los postulados iniciales. La globalización política no solo modifica las bases sobre las que se construyeron los Estados nacionales sino que las destruye. La salida a este múltiple impasse ¿pasa solo por el Estado? El "no hay política" significa declinación del Estado, sí, pero apunta sobre todo a una dificultad de hacer política y a la necesidad de hacerla de otra manera.

Si hubiera que elegir una de las dos lecturas del Ensayo, la primera resulta más asequible, menos vulnerable, porque como pronunciamiento o manifiesto frente a las "planificaciones globales", el Ensayo es consistente con la visión gongorina de la historia, y procura un poderoso instrumento hermenéutico para una lectura del presente. Hay, sin embargo, una concepción del Estado en esa interpretación, y es básicamente historicista: eso debilita la crítica del neoliberalismo. El hecho de que esa reforma del Estado se realice "desde arriba", sin tener en cuenta la "tradición" y "la idiosincrasia de los pueblos", no parece un criterio suficiente, porque la historia del Estado, desde el siglo XVI en adelante, y las Constituciones, desde la de 1833 hasta la de 1925 y 1981, se realizaron "desde arriba" y a espaldas del $\operatorname{demos}^{25}$.

25 Renato Cristi y Pablo Ruiz Tagle, La República en Chile. Teoría y práctica del constitucionalismo republicano. Lom, Santiago, 2006. 
Que el neoliberalismo debilita “orgánicamente" el Estado y termina desvirtuando la política es una idea casi profética, porque la mercantilización terminó privatizando la política misma: la redujo a "empoderamiento" y "emprendimiento". Si son los consorcios los que financian la política ¿puede extrañar que ésta responda a sus intereses y que los políticos jueguen su propio juego, el de reelegirse? El escenario mundial también es propicio: el fin de los "socialismos reales" favoreció la hegemonía mundial del neoliberalismo y el "discurso único".

\section{Apéndice I. Sobre la guerra}

El enfoque de la cuestión de la guerra en el Ensayo merece un comentario aparte. A pesar de la evidente molestia de Góngora frente a las ideologías y tendencias pacifistas que empiezan a imponerse en el siglo XX, y la actitud defensiva de la cancillería, él hace una 'lectura sintomática' de la guerra, es decir, la considera, siguiendo a Spengler, como un signo de fortaleza o decadencia ${ }^{26}$. Sobre todo en el siglo XVI y parte del XVII, la Guerra de Arauco le valió a Chile la reputación de ser "el Flandes indiano". En el siglo XIX, Chile habría hecho honor a su fama de "tierra de guerra"; ésta "pasa a ser un factor histórico capital: cada generación vive una guerra" 27 . Pero en el XX, sobrevino el "desvanecimiento del sentido patriótico-territorial en todos los estratos sociales" 28 . Se debilitó la capacidad expansiva que había mostrado el Estado en el siglo XIX. "El ethos republicano de la aristocracia del siglo XIX, heredado por la mesocracia radical [...] y por las cúpulas directivas de la Falange y Democracia Cristiana, se extingue en 'las bases" "29. Después de la Primera Guerra Mundial cobraron fuerza las ideas positivistas y humanistas que inspiraron los movimientos pacifistas. Este decaimiento del nacionalismo coincide, casi sobra decirlo, con el debilitamiento y desaparición del Estado portaliano, de modo que la pregunta por la pertinencia del reclamo por un "Estado vivo" u "orgánico" (Góngora), parece justificada. Sin desmerecer la importancia de la geopolítica diseñada por Portales, es preciso preguntar por la vigencia de su estrategia. Chile consiguió convertirse en un Estado relativamente equivalente a sus vecinos, gracias

26 La visión del hombre "animal de presa" (Spengler) resulta de una lectura biologista de Nietzsche; su idea de "decadencia" es más compleja que la de Spengler y no obstante, escribe: "la historia griega tiene en las guerras médicas su daemon ex machina" ("Últimos trabajos del año 1875" Werke, Musarion Ausgabe, Munich, 1920-1929, vol. VI, p. 114. Este texto no se encuentra en la edición de Carl Hansen en tres tomos).

27 Op. cit., p. 66. La guerra de conquista de los siglos XVI y XVII es formadora de "nación" en un sentido muy diferente a las "guerras nacionales" del período republicano. La Guerra contra la Confederación, "distó mucho de ser popular" (p. 70). La "pequeña guerra" contra España (1865) consistió en el bombardeo de Valparaíso y no produjo víctimas. Las guerras civiles 1851,1859 y 1891 , no tienen los efectos formadores de aquellas.

28 Op. cit., p. 239.

29 Op. cit., p. 278. 
a esa geopolítica, pero las guerras actuales son "guerras tecnológicas" o "de material" (Ernst Jünger), dejaron de ser artesanales y volvieron la destrucción y la matanza recíprocas. El cierre de Chile sobre sus fronteras responde sobre todo a la necesidad de consolidarlas; con eso ha tenido bastante trabajo. Mac Iver no es sospechoso de ser "pacifista hasta el escándalo" y ya en 1910 declaraba en La crisis moral de la nación: "Yo no admiro y amo el pasado de mi país, a pesar de sus errores y faltas, por sus glorias en la guerra, sino por sus virtudes en la paz". La tradición legal y civilista chilena está, sin duda, más acorde con los imperativos de la integración y la cooperación, que la guerra. Sería demasiado fácil, sin embargo, endilgarle a Góngora el nacionalismo guerrero del siglo XIX, cuando él solo lo consigna como un rasgo del Estado portaliano. Un Estado que él admira, pero no tiene por qué suscribir una política que sería hoy, más que un anacronismo, un error. "Solamente queremos, aclara, detenernos en la diferencia de actitud de Chile en torno a estos problemas durante el siglo pasado y durante éste" 30 . Cabría, sin embargo, preguntar: ¿Qué sería de la magnificación del "genio" de Portales y del Estado portaliano si se hubiera perdido la Guerra contra la Confederación? En la política más meditada y mejor ejecutada subsiste siempre un elemento fortuito $\mathrm{y}$, por tanto, hay cierto oportunismo en la glorificación del "gran hombre".

\section{Apéndice II}

¿Será posible una tercera lectura de este libro, a saber, como un mito fundacional? Un mito que replica el modelo bíblico de la creación ex nihilo, y de una caída a partir de un estadio inicial de gracia. La venida de un Salvador redime transitoriamente una humanidad manchada por un pecado original: la carencia de "virtud republicana". A pesar de este efecto redentor, no se consigue desterrar el mal endémico. La escatología cristiana también quiere ver en la historia y en los males que genera algún motivo redentor, pero en lo esencial, es Satán el Señor de la Tierra; es Cristo, no Satán, quien dijo: "mi reino no es de este mundo". Cristo no consigue instaurar su propio reinado hasta el momento del Juicio Final. La humanidad no tiene salvación terrenal: es una raza maldita, sin redención en este mundo -lo sospecharon también los griegos-, la salvación opera solo en diferido, en el 'más allá'. El poder es el origen del mal y está presente en todo, lo invade todo, incluso el Reino Celestial: Satán es originalmente un ángel caído. Dios no puede querer el mal, pero el ángel maligno sí: quiere igualarse a Dios; su voluntad de poder es el origen del mal.

Portales sería entonces, la metáfora del Salvador, el "genio" creador, el homo nationalis capaz de suplir la carencia de virtud del pueblo con su propia y superlativa virtud. "El Estado portaliano es la religión del ejecutivo omnipotente" (Isidoro Errázuriz $)^{31}$; divide la historia en un "antes" y un "después": un pasado lastrado con "el

Op. cit., p. 223.

Isidoro Errázuriz, Juicio político sobre don Diego Portales, en Ensayo...op. cit., p. 77. 
peso de la noche" y un "después" que logra apartar el "cáliz" de la anarquía y la "noche" iniciales. Sigue un ascenso fulgurante y luego la caída, lenta, pero inexorable. Encina, que también suscribe la interpretación de Edwards, prefirió suspender el relato en el cénit, en 1891, cuando concluye el régimen portaliano; quiso evitar el gusto amargo del tramo final. Dedicó diez volúmenes de los diecinueve que componen su Historia de Chile al período republicano.

\section{Referencias bibliográficas}

Anderson, Benedict (1993), Comunidades imaginadas. México: Fondo de Cultura Económica.

Balibar, Etienne (1990), Race, nation, clase. Les identités ambigües. París: La Découverte.

Cristi, Renato y Pablo Ruiz Tagle (2006), La República en Chile. Teoría y práctica del constitucionalismo republicano. Santiago: Lom.

Deleuze, Gilles, Nietzsche et la philosophie, PUF, Paris 1962 (Nietzsche y la filosofia. Barcelona: Anagrama, 1971).

Edwards Vives, Alberto (1992), La fronda aristocrática. Santiago: Editorial Universitaria.

Foucault, Michel, Nietzsche, la généalogie, l'histoire, PUF, Paris 1971 (Nietzsche, la genealogía, la historia. Pre-Textos, Valencia 2000).

Gellner, Ernest (1965), Thought and Change. Londres.

Góngora, Mario (2003), Ensayo histórico sobre la noción de Estado en Chile en los siglos XIX y XX. Santiago: Editorial Universitaria (Octava Edición).

Guerra, Francisco Xavier (1995), "La nación en América Hispana", Nación y modernidad. Buenos Aires: Nueva Visión.

Hobsbawm, Eric (2004), Naciones y nacionalismo desde 1780. Barcelona: Crítica.

Kant (2004), Hacia la paz perpetua, trad. María Cristina García, Buenos Aires: Ladosur, pp. 55-56.

Kant (1986), La religión dentro de los límites de la mera razón. Madrid: Alianza, p. $205 n$.

Kedourie, Elie (1985), Nationalism. Londres: Blackwell Publishers.

Nietzsche (1960), Unzeitgemässe Betrachtungen "Von Nutzen und Nachteil der Historie für das Leben", Werke in drei Bänden, Karl Hanser Verlag, München, (Intempestivas, "De la utilidad y desventaja de los estudios históricos para la vida", Obras, Madrid: Alianza).

Paz, Octavio (1983), Tiempo nublado. Barcelona: Seix Barral.

Portales, Diego (2007), Epistolario, Santiago: Ediciones de Universidad Diego Portales.

Renan, Ernest (1882), Qu'est-ce qu'une nation? Paris (Qué es una nación, Ed. Elevación), Buenos Aires, 1947). 